PROGRAMME FOR INTERNATIONAL STUDENT ASSESSMENT

\title{
PISA FOR DEVELOPMENT
}

Results in Focus

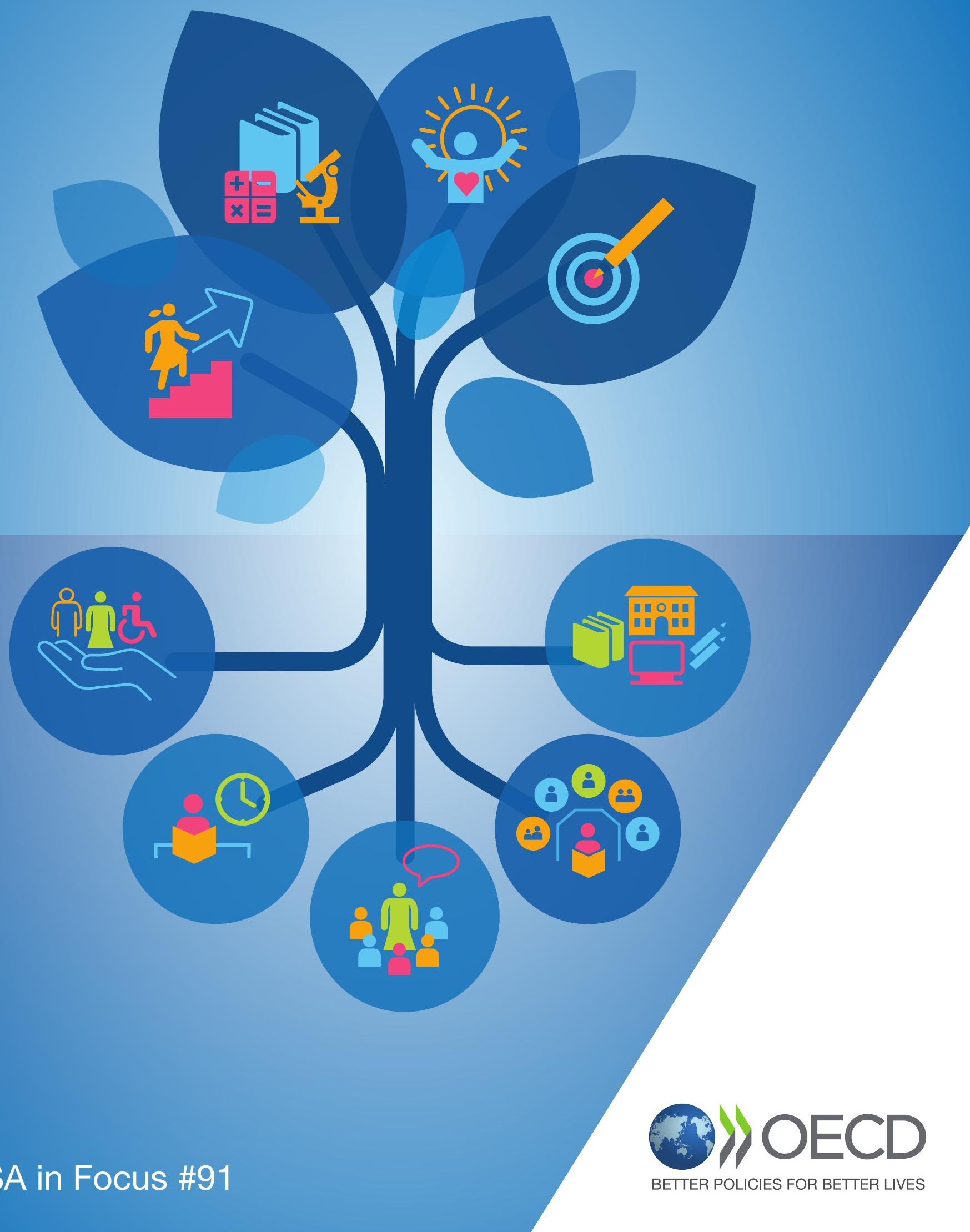


Over the past two decades, the OECD Programme for International Student Assessment, PISA, has become the world's premier reference for evaluating the quality, equity and efficiency of school systems. By identifying the characteristics of highperforming and improving education systems, PISA allows governments and educators to identify effective policies that they can adapt to their local contexts. PISA is now being used by the UN system as a major source of data for monitoring progress towards the Sustainable Development Goals (SDGs) established by the international community as the blueprint to achieve a better and more sustainable future for all.

PISA for Development (PISA-D), the latest of the OECD's PISA assessments, focuses on making PISA more accessible and relevant to low-to-middle-income countries. We have enhanced our PISA instruments so that they target the range of student performance in these countries. We have also collected background information to capture how students learn, teachers teach and schools operate in these contexts. PISA-D has also helped the participating countries to build their capacity to manage large-scale assessments and to make use of the results in support of national policy dialogue and education policy-making.

The countries participating in PISA-D have demonstrated great courage in comparing themselves globally, as well as firm commitment to understanding the results. All of them have reached the standards of technical quality for the survey implementation that we had set for the most advanced education systems. Some have even achieved results that were far better than what the level of resources they can afford to invest in education would suggest.

This brochure highlights some of the results from PISA-D in seven participating countries from Africa, Latin America and Asia. It highlights the important educational challenges these countries will have to address: only around $23 \%$ of students across the PISA-D countries attain at least the minimum level of proficiency in reading, compared with the OECD average of $80 \%$. The PISA-D results also tell us what is possible in education in 
the participating countries and highlight some of the factors that can drive improved outcomes, such as: eliminating grade repetition, particularly among boys, ensuring quality learning time and allocating resources more equitably.

At the OECD, we have learned a great deal from the PISA-D exercise. Specifically, the PISA-D countries have helped us increase resolution and relevance of the PISA instruments for low performers in OECD countries. More generally, all countries in PISA have been benefitting from the opportunity PISA-D has provided for including more diversity in policies and practices, enriching analyses by having a greater range of points of comparisons and also increasing the opportunities for peer learning.

We have already integrated the outputs of PISA-D in the main PISA assessment. This helped the OECD both to incorporate increasing numbers of participants in the assessment and to offer existing participants a wider range of benefits, such as capacity building for data analysis and reporting and the inclusion of out-of-school youth.

The education systems of the PISA-D countries, and low-to-middle-income countries more generally, have the potential to ensure that all of their children and young people achieve at least minimum levels of proficiency in basic skills, such as literacy and numeracy. We have no time to lose in ensuring that these systems commit themselves to providing the best education possible. The OECD stands ready to support the PISA-D countries in their efforts to achieve better education policies for better lives.
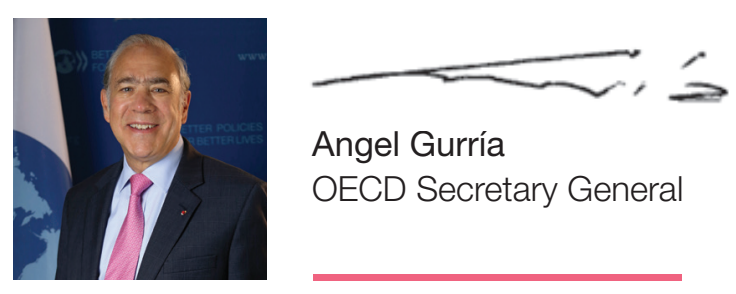
Angel Gurría OECD Secretary General 


\section{What are PISA and PISA for Development?}

"What is important for citizens to know and be able to do?" In response to that question and to the need for internationally comparable evidence on student performance, the Organisation for Economic Co-operation and Development (OECD) launched the triennial survey of students around the world known as the Programme for International Student Assessment, or PISA. PISA assesses the extent to which 15-year-old students, near the end of their compulsory education, have acquired key knowledge and skills that are essential for full participation in modern societies. The assessment focuses on the core school subjects of reading, mathematics and science. The assessment does not just ascertain whether students can reproduce knowledge; it also examines how well students can extrapolate from what they have learned and apply that knowledge in unfamiliar settings, both in and outside of school. This approach reflects the fact that modern economies reward individuals not for what they know, but for what they can do with what they know.

Building on the experience of working with middle-income countries in PISA since 2000, and in an effort to respond to the emerging demand for PISA to cater to a wider range of countries, the OECD launched the PISA for Development (PISA-D) initiative in 2014. This one-off pilot project, spanning six years, aims to make the assessment more accessible and relevant to low-to-middle-income countries. To accomplish its objectives, the project:

- provides a more granular definition of student performance at the lower end of the PISA scales

- captures a wider range of social and economic contexts

- incorporates an assessment of out-of-school 14-16 year-olds

- builds capacity in the participating countries for managing and using the results of large-scale assessments

- supports the monitoring and achievement of the Sustainable Development Goal for education (SDG 4).
Seven countries participated in the school-based implementation of PISA-D: Cambodia, Ecuador, Guatemala, Honduras, Paraguay, Senegal and Zambia. ${ }^{1}$ One of the main reasons for their participation is policy makers' wish to understand why students in their countries achieve certain levels of performance. Assessment results provide policy makers with data and evidence that can be used to determine what they can do to improve their education systems and, ultimately, ensure that their students acquire the skills needed to succeed in school and in life.

This brochure reflects the in-school assessment results for PISA-D. The out-of-school data were collected after those of the in-school assessment and will be reported at a later date. 

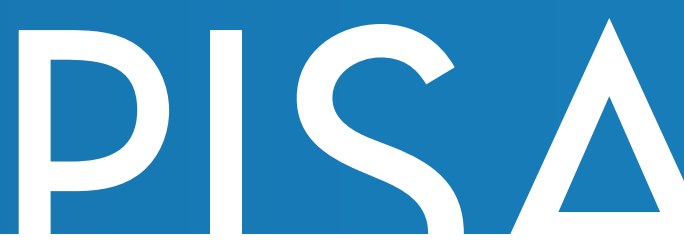

\section{Key features of PISA-D}

\section{Content}

The PISA-D school-based survey assessed students in reading, mathematics and science; each domain was treated equally in the assessment.

\section{Participating students}

Around 37000 students completed the school-based assessment, representing about one million 15-year-old students (in grade 7 or above) in the schools of the seven participating countries: Cambodia, Ecuador, Guatemala, Honduras, Paraguay, Senegal and Zambia.

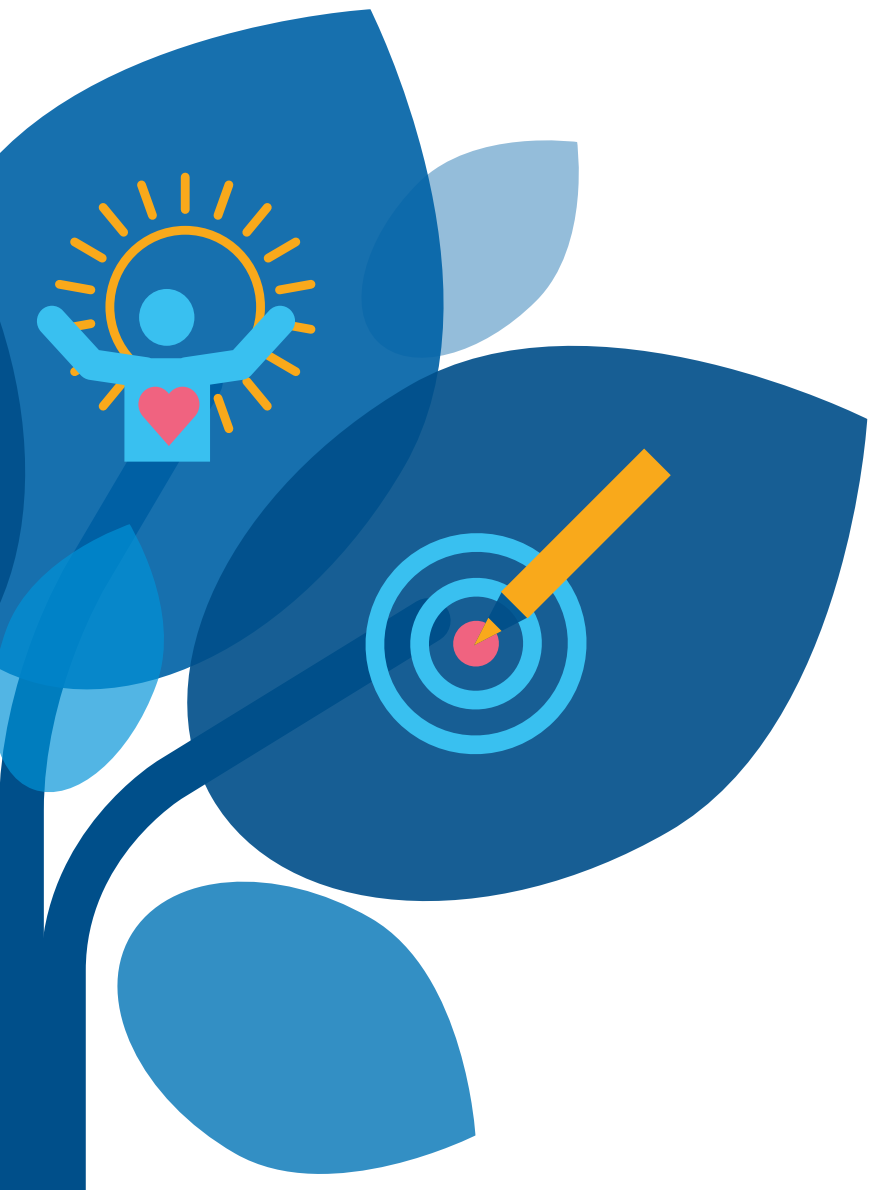

\section{The assessment}

- Paper-based tests were used, with assessments lasting a total of two hours for each student.

- Test items were a mixture of multiple-choice questions and questions requiring students to construct their own responses. The items were organised in groups, each group based on a passage that set out a real-life situation. The school-based assessment drew on about 200 test items, with different students taking different combinations of test items.

- More than half of the assessment items were identical to the items used in the PISA 2015 paper-based assessment, which allowed for reporting of results on the PISA scale through scale-linking methods. The remaining items included adapted PISA items (e.g. with extended scoring rubrics) and items used in other OECD skills assessments that were evaluated against PISA frameworks.

- The tests were targeted at the lower levels of performance as measured on the PISA scale. In the PISA-D test, more than twothirds of the items were at Level 2 or below; less than one-third of the items were at Level 3, 4, 5 or 6. Level 2 marks the level of proficiency at which students begin to demonstrate the competencies that will enable them to participate effectively and productively in life as continuing students, workers and citizens. In relation to SDG 4, Level 2 is considered the minimum level of proficiency in reading and mathematics that all children should attain by the end of lower secondary school.

- Students also answered a background questionnaire, which took 35 minutes to complete. The questionnaire sought information about the students themselves, their well-being, educational attainment, and attitudes towards school and learning, their homes, their families, and their school and learning experiences. School principals completed a school questionnaire that describes the school, its students and teachers, and the learning environment. Teachers also completed a questionnaire about themselves, the school's resources, their teaching practice and their students.

\section{Building country capacity for education assessments}

A key component of PISA-D was building capacity in the participating countries for managing large-scale student learning assessments and using the results to support national policy dialogue and evidence-based decision-making. National centres received support for conducting the assessment, analysing its results and disseminating the findings. The capacities strengthened through PISA-D are relevant to countries' management of their own national assessments and other large-scale international or regional assessments in which they might participate. 


\section{Findings from the PISA for Development school-based assessment}

The PISA-D school-based assessment results were published for the first time in national reports produced by the participating countries in collaboration with the OECD. All national reports were released in December 2018. This brochure provides a comparative overview of the main results and, wherever possible, compares these to the OECD average for the PISA 2015 assessment cycle. ${ }^{2}$ However, some of the data for PISA-D, such as student health status, do not have an equivalent in PISA.

\section{Educational attainment at age 15}

- On average across PISA-D countries, only $43 \%$ of all 15 -year-olds were enrolled in at least grade 7 by age 15 and were eligible to sit the PISA-D test, compared to the OECD average of $89 \%$. The remaining 15-year-olds were either in grades below 7 or were out of school. In Cambodia, Senegal and Zambia, only around 30\% of 15-year-olds were eligible to sit the PISA-D test.

- In Ecuador, Paraguay and Zambia, about as many boys as girls were in school, in grade 7 or above, at age 15. In Cambodia, Honduras and Senegal, the number of girls eligible to sit the PISA test exceeded the number of boys by $10 \%$ or more; in Guatemala, the number of boys exceeded the number of girls by $10 \%$ or more.

- On average across PISA-D countries, only $62 \%$ of students who sat the PISA-D test were enrolled in the expected grade or in a higher grade, given their age. Many of the students who had fallen behind reported that they had repeated a grade at least once in primary or lower secondary school.

- The percentage of students who reported having repeated a grade at least once ranged from $18 \%$ in Ecuador to $50 \%$ in Senegal higher percentages than across OECD countries (12\%), on average. In Cambodia, Ecuador, Guatemala, Honduras and Paraguay, boys were more likely than girls to have repeated a grade.

\section{Students' performance in reading}

- About $23 \%$ of students across PISA-D countries achieve the minimum level of proficiency in reading, compared with the OECD average of $80 \%$. In Ecuador, 49\% of students reached this level - the highest percentage among PISA-D countries, and a similar percentage to that in Brazil in PISA 2015. As envisaged in SDG 4, all children and young people should attain at least the minimum level of proficiency (Level 2) by the time they complete lower secondary education. At Level 2 in PISA, students can read simple and familiar texts and understand them literally. They can also demonstrate, even in the absence of explicit directions, some ability to connect several pieces of information, draw inferences that go beyond the explicitly stated information, and connect a text to their personal experience and knowledge.
- In Ecuador, Guatemala, Honduras and Paraguay, Level 1a was the median reading proficiency level among students. This means that more than half of the students could, at best, retrieve pieces of information that are explicitly stated, identify the main theme or the author's intent in a text about a familiar topic, or make a simple connection by reflecting on the relationship between information in the text and common, everyday knowledge. Students at this level perform below the baseline in reading, but not too far from it.

- In Cambodia, Senegal and Zambia, the median reading proficiency among students was Level 1b, meaning that more than half of the students could, at best, solve the easiest text-comprehension tasks included in the PISA-D assessment, such as retrieving a single piece of explicitly stated information, e.g. from the title of a simple, familiar text or from a straightforward list. In these three countries, more than $10 \%$ of students scored below this level. Many of them demonstrated the ability to comprehend short sentences or passages literally, but were unable to read and understand longer texts or to make simple inferences.

- While most students in the PISA-D countries scored at the lower levels of proficiency, $7 \%$ of 15 -year-olds in PISA-D countries, on average, demonstrated high levels of knowledge and skills in reading, meaning that they scored at or above Level 3 - the typical level of proficiency among 15-year-old students in OECD countries. The challenge for PISA-D countries is to increase the share of their students who perform at these higher levels.

\section{Students' performance in mathematics}

- About $12 \%$ of students across PISA-D countries achieve the minimum level of proficiency in mathematics, compared with the OECD average of $77 \%$. As envisaged in SDG 4, all children and young people should attain at least the minimum level of proficiency (Level 2) by the time they complete lower secondary education. Level 2 in PISA corresponds to a level at which students can not only carry out arithmetic operations in situations where all the instructions are given to them, but can also interpret and recognise how a (simple) situation (e.g. comparing the total distance across two alternative routes, or converting prices into a different currency) can be represented mathematically. 


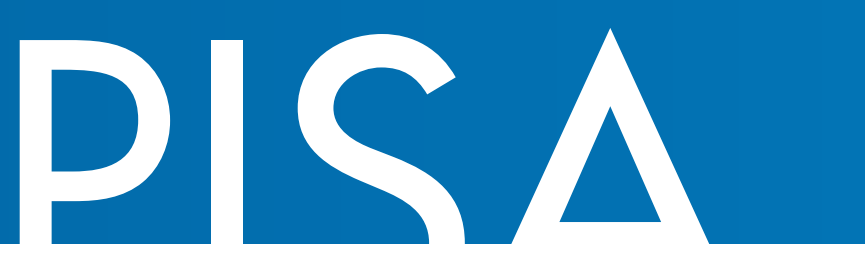

- In Ecuador, the highest-performing PISA-D country, Level 1a was the median mathematics proficiency level among students. At this level, students can perform routine tasks in well-defined situations, where the required action is usually obvious (such as computing the total distance of a route, or how to split a bill equally among a small number of people).

- In Cambodia, Guatemala, Honduras, Paraguay and Senegal, the median mathematics proficiency level was $1 \mathrm{~b}$, at which students demonstrate that they are able to follow clearly prescribed instructions given in a simple text and sometimes perform the first step of a two-step solution of a mathematical problem.

- In Zambia, Level 1c was the median mathematics proficiency level. Most students in this country could only understand mathematics questions involving simple, everyday contexts where all relevant information is clearly given and defined in a very short simple text. They were able to follow a single clearly prescribed instruction to perform a single step or operation (such as reading a single, clearly labelled value, from a simple chart or table, e.g. a price in a short menu).

- In all PISA-D countries, less than $10 \%$ of students attained the OECD average PISA 2015 mathematics score.

\section{Students' performance in science}

- About $18 \%$ of students across PISA-D countries achieve the minimum level of proficiency (Level 2) in science, compared with the OECD average of 79\%. Level 2 in PISA corresponds to a level at which students can draw on their knowledge of basic science content and procedures to identify an appropriate explanation, interpret data, and identify the question being addressed in a simple experiment. All students should be expected to attain at least Level 2 in science by the time they leave compulsory education

- In Ecuador, Guatemala, Honduras and Paraguay, Level 1a was the median science proficiency level among students. At this level, students can use common content and procedural knowledge to recognise or identify explanations of simple scientific phenomena. With support, they can undertake a scientific enquiry with no more than two variables (e.g. an input and an output variable). They can identify simple causal or correlational relationships and interpret graphical and visual data that require a low level of cognitive ability. Students at Level 1a can select the best scientific explanation for given data in familiar contexts

- In Cambodia, Senegal and Zambia, the median science proficiency level was $1 \mathrm{~b}$, at which students demonstrate they can use common content knowledge to recognise aspects of simple scientific phenomena. They can identify simple patterns in data, recognise basic scientific terms and follow explicit instructions to carry out a scientific procedure.

\section{Snapshot of performance in reading, mathematics and science}

\begin{tabular}{|c|c|c|c|c|c|c|}
\hline & \multirow[b]{2}{*}{$\begin{array}{l}\text { Mean reading } \\
\text { score }\end{array}$} & \multirow[b]{2}{*}{$\begin{array}{l}\text { Mean } \\
\text { mathematics } \\
\text { score }\end{array}$} & \multirow[b]{2}{*}{$\begin{array}{l}\text { Mean science } \\
\text { score }\end{array}$} & \multirow{2}{*}{$\begin{array}{l}\text { Coverage of the } \\
\text { national 15-year-old } \\
\text { population } \\
\text { (PISA Coverage } \\
\text { index } 3 \text { ) }\end{array}$} & \multicolumn{2}{|c|}{$\begin{array}{l}\text { Education Sustainable Development } \\
\text { Goal (SDG 4) indicator }\end{array}$} \\
\hline & & & & & $\begin{array}{l}\text { Students achieving } \\
\text { minimum level of } \\
\text { proficiency (Level 2) } \\
\text { in reading }\end{array}$ & $\begin{array}{l}\text { Students achieving } \\
\text { minimum level of } \\
\text { proficiency (Level 2) } \\
\text { in mathematics }\end{array}$ \\
\hline & Mean & Mean & Mean & $\%$ & $\%$ & $\%$ \\
\hline Cambodia & 321 & 325 & 330 & 28.1 & 7.5 & 9.9 \\
\hline Ecuador & 409 & 377 & 399 & 60.6 & 49.4 & 29.1 \\
\hline Guatemala & 369 & 334 & 365 & 47.5 & 29.9 & 10.6 \\
\hline Honduras & 371 & 343 & 370 & 41.4 & 29.7 & 15.4 \\
\hline Paraguay ${ }^{1}$ & 370 & 326 & 358 & $\mathrm{~m}$ & 32.2 & 8.3 \\
\hline Senegal & 306 & 304 & 309 & 29.0 & 8.7 & 7.7 \\
\hline Zambia & 275 & 258 & 309 & 36.0 & 5.0 & 2.3 \\
\hline OECD average & 493 & 490 & 493 & 89.0 & 79.9 & 76.6 \\
\hline $\begin{array}{l}\text { Lower-middle } \\
\text { income average }\end{array}$ & 378 & 368 & 392 & 60.2 & 37.7 & 28.7 \\
\hline
\end{tabular}

${ }^{1}$ In Paraguay, the percentage of 15 -year-olds covered by the PISA sample (Coverage index 3) may be significantly under-estimated and subject to future revision (see the chapter on "Sampling outcomes" in the forthcoming PISA for Development Technical Report).

Source: PISA 2015 and PISA for Development Databases. 


\section{Variation in student performance}

Equity in education requires that all children have access to education opportunities that lead to quality learning outcomes, irrespective of their gender, their ethnicity, or their parents' wealth, education or occupation. Thanks to detailed information about the background of participating students, PISA and PISA-D can compare learning outcomes and education opportunities across the student population. But such comparisons offer only a partial description of inequalities and unfair opportunities that affect the education of young people. A fuller analysis would also require information about those 15-year-olds who are not covered by PISA samples (equity in access to the system). These 15-year-olds are the subject of the out-of-school component of PISA-D, whose results will be reported in December 2019.

Among the 15-year-olds eligible to sit the PISA-D test:

- Girls tended to outperform boys in reading (except in Senegal, where boys and girls performed similarly in reading), but the gender gap in reading performance was often less pronounced across PISA-D countries than in OECD countries: the largest gap, in Cambodia (17 score points), was smaller than the average gap across OECD countries (27 score points). Most PISA-D countries had a gender gap in mathematics performance in favour of boys (except Cambodia and Zambia, where boys and girls performed similarly in mathematics). The gender gap in mathematics was relatively pronounced in Ecuador and Honduras (20 score points). There was a small gender gap in science performance only in Cambodia (in favour of girls), Ecuador and Honduras (in favour of boys).

- In all PISA-D countries, students attending urban schools outperformed students in rural schools in reading, with an average performance difference of 42 score points, the equivalent of more than a year of schooling.

- The mean performance of students at different levels of socioeconomic status (as measured by the PISA index of economic, social and cultural status) shows that students in PISA-D countries tend to do worse than students across OECD countries with similar socio-economic resources. In particular, the most advantaged students in PISA-D countries systematically performed below similarly advantaged students in OECD countries.

- While the range of student performance across the different levels of socio-economic status is smaller in PISA-D countries than OECD countries, on average, socio-economic status still has considerable impact on performance in PISA-D countries. Socioeconomically advantaged students (the top 25\%) across PISA-D countries were, on average, five times more likely than disadvantaged students (the bottom 25\%) to attain the minimum level of proficiency (Level 2) in mathematics. Very few disadvantaged students achieved minimum levels of proficiency and even fewer scored among the best in their countries.

\section{Reading performance and family resources in PISA-D countries}

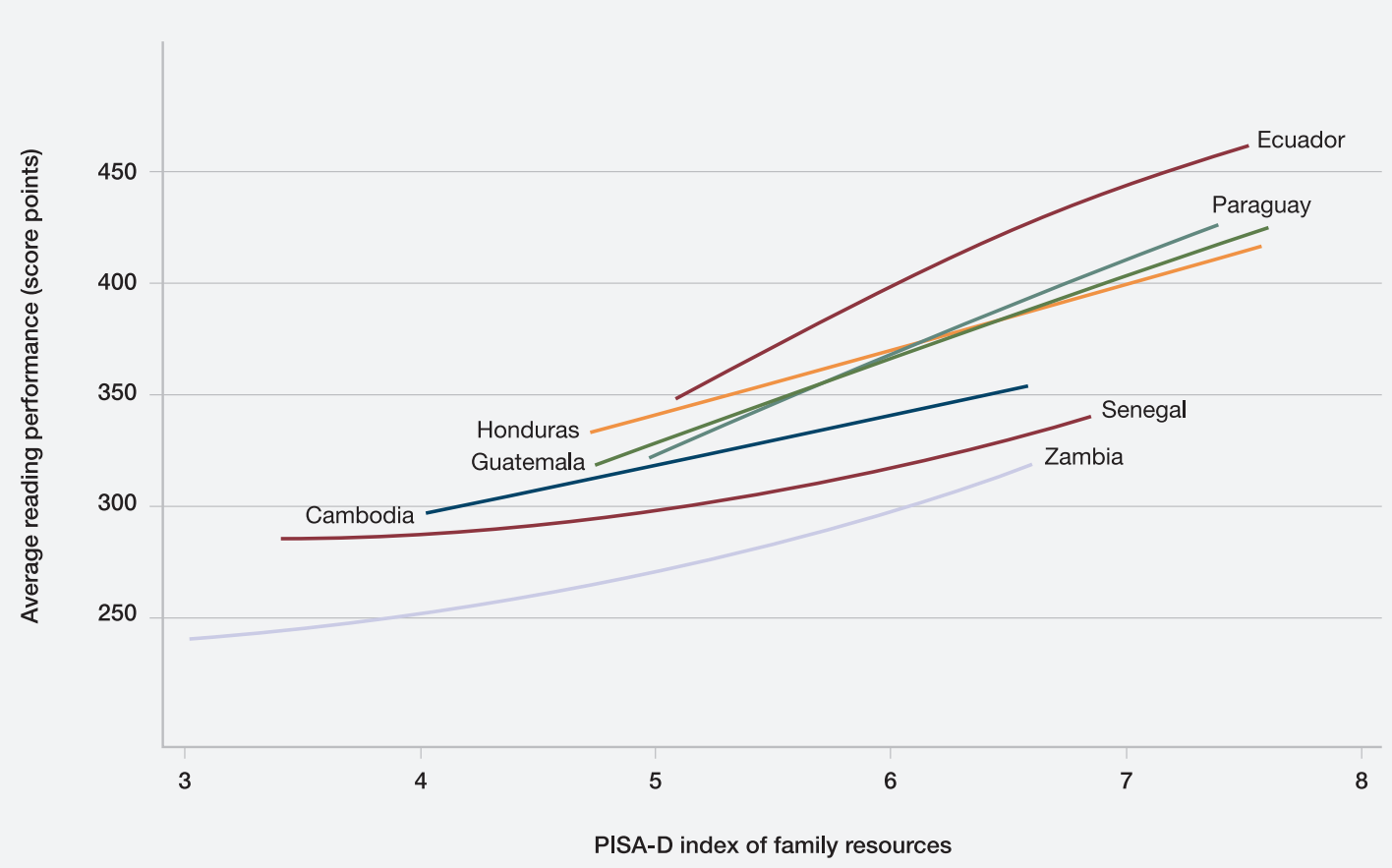

Note: Each curve represents the average level of performance for students at different levels of the PISA-D index of family resources. The average in this figure is based on a quadratic regression model, and is represented between the country's 5th and 95th percentile of the PISA-D index of family resources. Students with an index value below 5 are considered severely poor.

Source: PISA for Development Database. 
- Keeping in mind that across the PISA-D countries only $43 \%$ of all 15-year-olds were eligible to sit the test (compared to the OECD average of $89 \%$ ), the range of performance across the different levels of socio-economic status would likely be significantly wider in PISA-D countries if it included the performance of those 15-year-olds that were ineligible.

- PISA-D also extended the PISA measure of socio-economic status through an index of family resources, which considers not only possessions that indicate high status, but also the extent to which students' basic needs, such as food security and quality shelter (e.g. access to a toilet in their home) are fulfilled. Students whose PISA-D index of family resources is below 5 , meaning that they were unlikely to have access to flush toilets or to a room with a bath or shower in their homes, and unlikely to possess a washing machine or a refrigerator, are considered to be "severely poor", and score, in all countries, significantly below non-poor students. The percentage of "severely poor" students ranges from $4 \%$ in Ecuador to over $40 \%$ in Cambodia, Senegal and Zambia.

- A significant minority of students in Guatemala (9\%) and Paraguay (41\%) reported that they do not speak the language of instruction
(Spanish) at home. In Senegal and Zambia, the vast majority of students reported that they do not speak the language of instruction at home: only $6 \%$ of students in Senegal reported speaking French at home, and $17 \%$ of students in Zambia reported speaking English at home. In these countries, students who speak the language of instruction at home scored significantly higher in reading than students who speak a different language at home, even after accounting for students' socio-economic status and family resources.

\section{Health, well-being and attitudes towards school and learning}

- Across PISA-D countries, around 89\% of students, on average, reported that they are satisfied with their life; 84\% reported that they are in good health. On scales that range from 0 to 10, they reported 7.9, on average, for life satisfaction (slightly higher than the OECD average of 7.3) and 6.9 for health (this measure is unique to PISA-D; there is no comparable OECD average).

- In all PISA-D countries, disadvantaged students were more likely than advantaged students to report poor or fair health.

\section{Socio-economic differences in self-rated health across PISA-D countries}

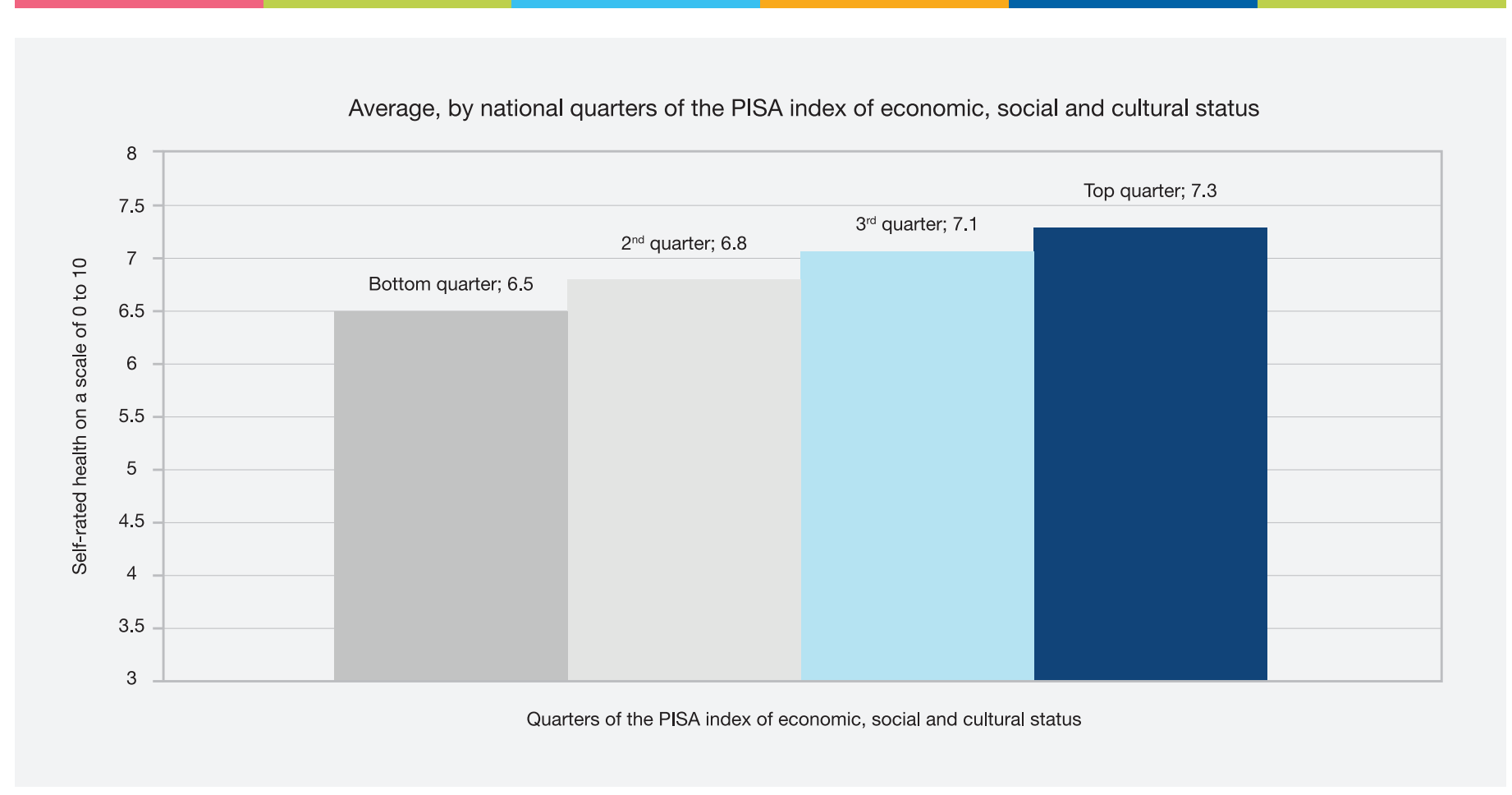

Source: PISA for Development Database. 
- Many students across PISA-D countries reported having felt hungry at least once in the month prior to the PISA test because there was not enough food. The largest shares of such students were observed in Cambodia (34\%), Senegal (35\%) and Zambia (53\%). The important role nutrition plays in learning has been well established: consuming the required amount of food contributes positively to students' concentration and commitment to learning. Food insecurity is therefore a significant threat to students' health, well-being and achievement.
- In all PISA-D countries except Zambia, girls were more likely than boys to report feeling sad or depressed at least once a week; on average, $46 \%$ of girls reported so, compared to $33 \%$ of boys.

- Most of the students assessed in PISA-D countries hold positive views about school and what they have learned. On average, 96\% of students reported that they believe that trying hard at school is important.

\section{5-year-old students' self-reported health and life satisfaction across PISA-D countries}

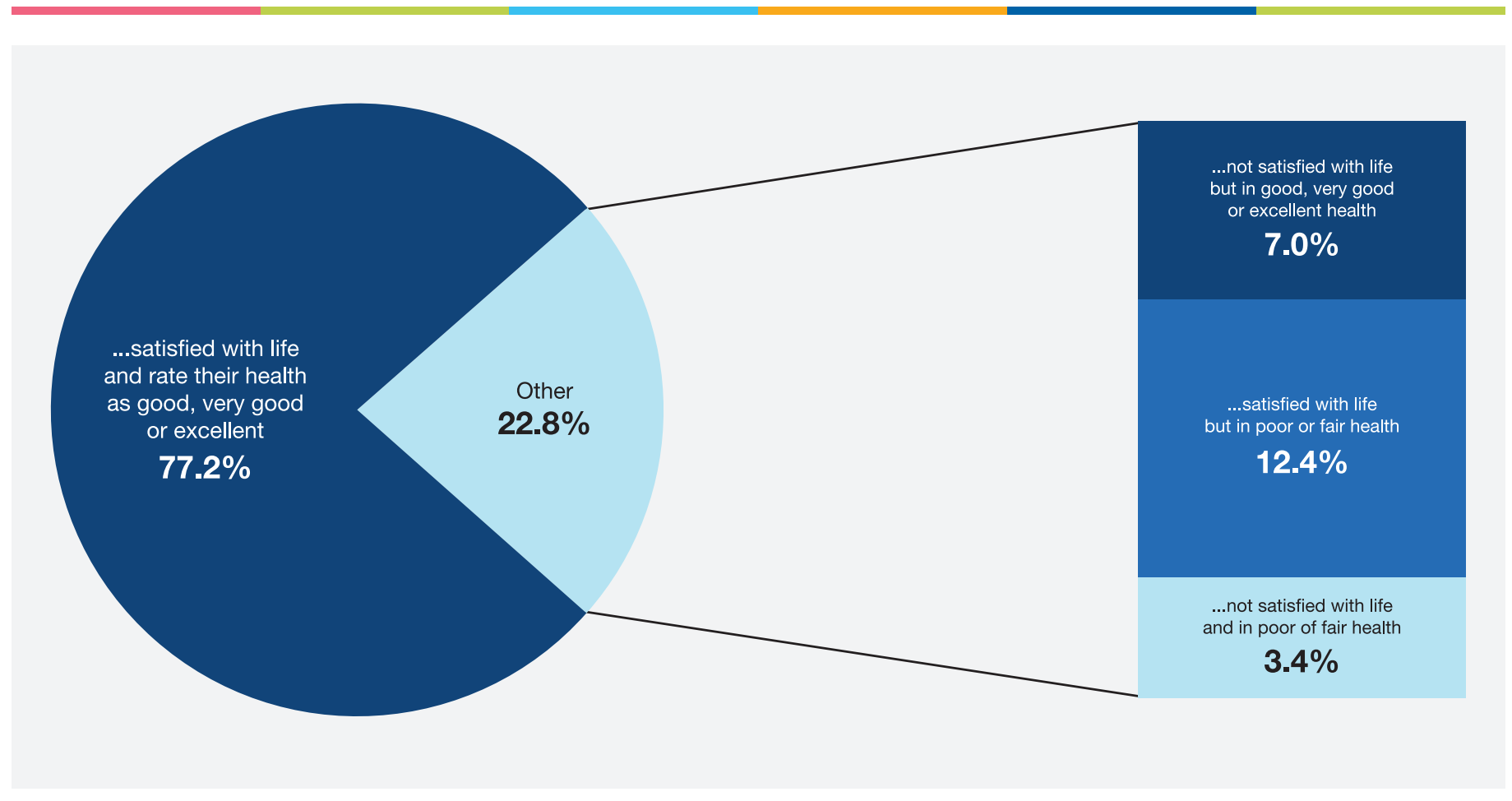

Source: PISA for Development Database. 

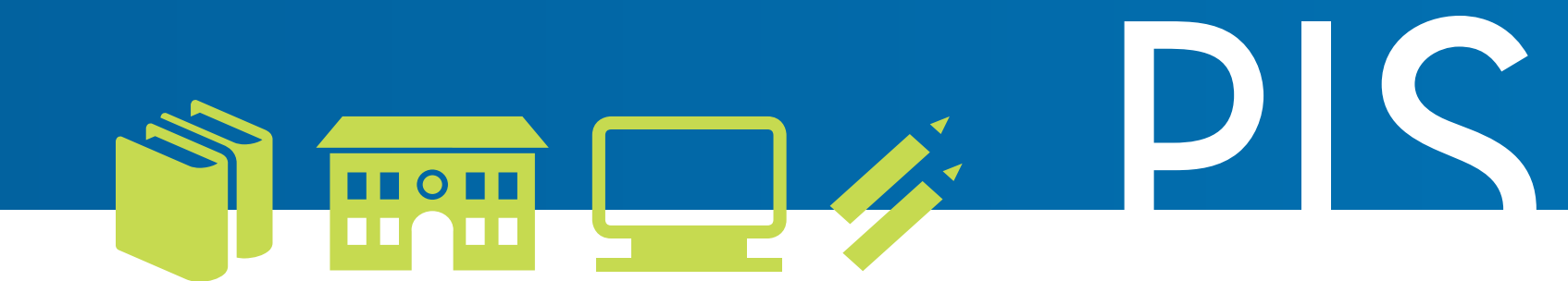

Students' performance on the PISA-D tests at age 15 is the result of an accumulation of various factors that affect children's development, beginning at conception and continuing through to the time of the assessment. For example, children's cognitive and language skills upon entering primary school are strong predictors of whether they become successful readers two or three years later; and pupils' reading skills at the end of primary school are a strong predictor of reading skills at age 15. Therefore, caution is advised when considering, for example, whether school or classroom practices, gleaned from responses to questionnaires distributed with the PISA-D test, have strong relationships with reading performance.

However, it is possible to identify a range of factors that influence student performance and related outcomes. The "educational prosperity" framework used by PISA-D identifies five such factors that it calls "foundations for success": resources, inclusive environments, learning time, quality instruction, and family and community support. PISA-D provides evidence of how these factors are related to 15-year-old students' performance.

The countries participating in PISA-D benefit by understanding how well their students fare compared with students in other countries. The results of PISA-D allow participating countries to determine whether their policies differ from those of countries with a similar social and economic context, but whose students perform better and benefit from more equitable learning opportunities. These comparisons can often provide valuable peer learning, and can sometimes help strengthen a country's political will to invest resources in education and/or identify effective policies that they can adapt to their particular contexts.

\section{Educational prosperity}

The "educational prosperity" approach inspired the contextual questionnaires for PISA-D. This approach considers the conditions needed for education systems to help students succeed in school and in life. It identifies a set of four key outcomes, called "prosperity outcomes", for each stage of schooling and child development: educational attainment; academic performance; health and well-being; and attitudes towards school and learning. The prosperity approach also identifies a set of family, institutional and community factors, called "foundations for success", that influence these outcomes: resources, inclusive environments, learning time, quality instruction, and family and community support.

Source: OECD (2018), PISA for Development Assessment and Analytical Framework: Reading, Mathematics and Science, OECD Publishing, Paris,

http://dx.doi.org/10.1787/9789264305274-en.

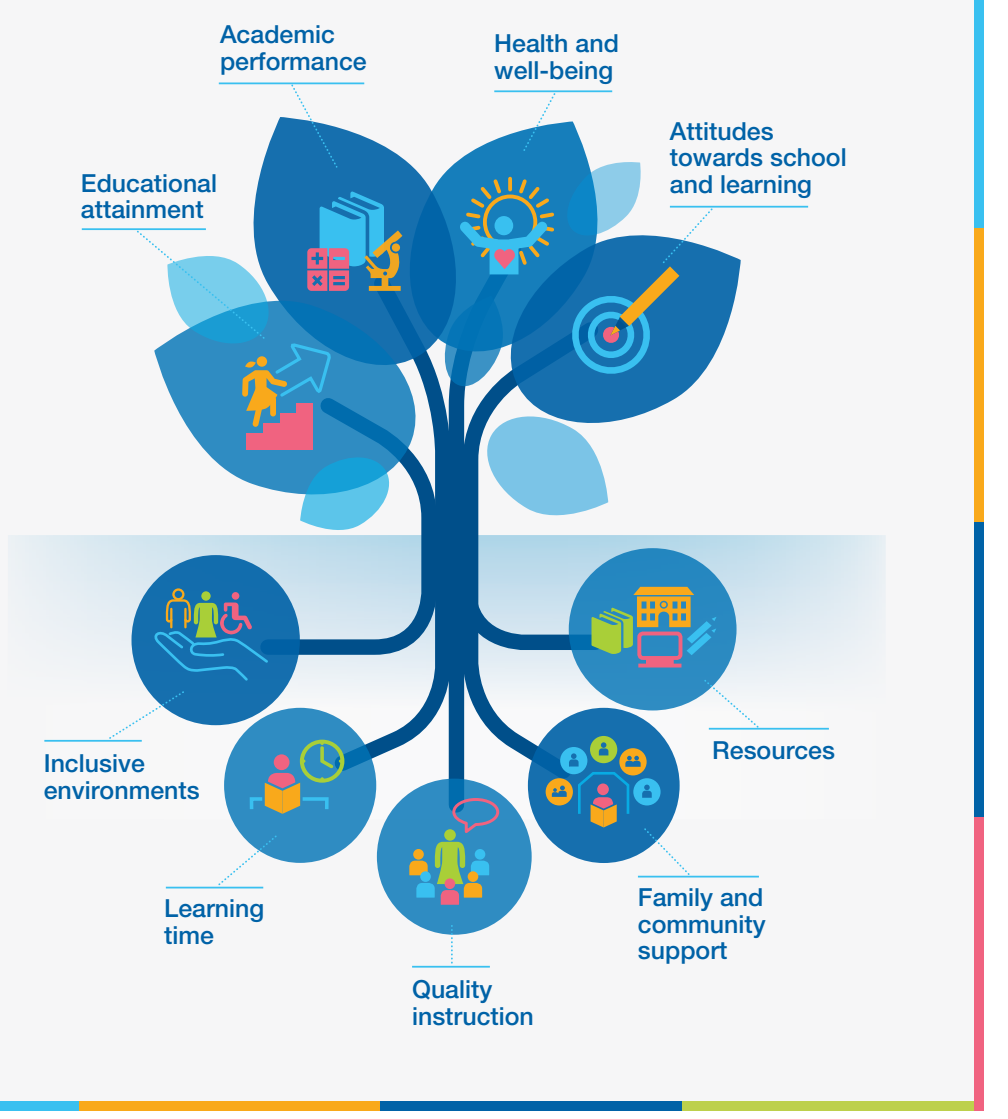

What the data tell us about foundations for success in the PISA-D countries

\section{Resources invested in education}

Financial resources for education can be allocated to salaries paid to teachers, administrators and support staff; maintenance or construction costs of buildings and infrastructure; and ancillary services, such as transportation and meals for students.
- In PISA-D countries, public expenditure on education as a percent of total public expenditure ranges from 12.8\% in Ecuador to $23.7 \%$ in Senegal. Public expenditure on education as a percent of GDP ranges from 2.7\% in Cambodia to 7.1\% in Senegal. In 2014, public expenditure on education globally was $14.1 \%$ of total public expenditure; in 2015, the median public expenditure on education globally was $4.7 \%$ of GDP. 


\section{Spending per student from the age of 6 to 15 and mathematics performance}

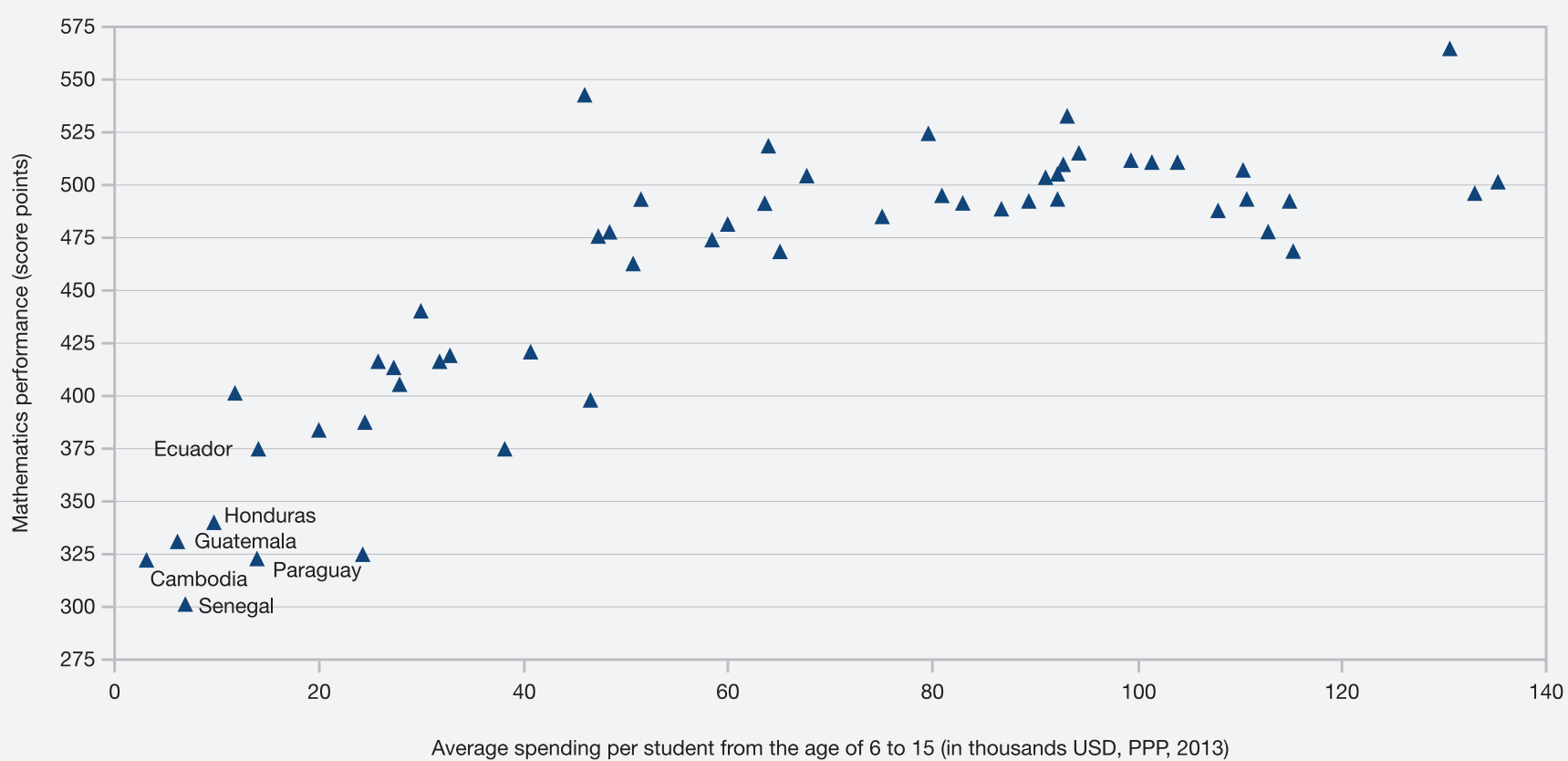

Note: Data for Zambia are missing. Data points without labels correspond to PISA 2015 countries with available data. Data for Switzerland and Luxembourg are not displayed on the chart, as the expenditure per student from the age of 6 to 15 in these two countries exceeds 140000 USD (PPP).

Source: PISA 2015 and PISA for Development Databases.

- Across OECD countries, 15-year-old students attend schools where there are, on average, 13 students for every teacher. Average student-teacher ratios range from almost 30 students per teacher in Brazil, Colombia, the Dominican Republic and Mexico, to fewer than 10 students per teacher in Albania, Belgium, Greece, Hungary, Iceland, Luxembourg, Malta and Poland. For PISA-D countries, the average student-teacher ratio can be high: in Cambodia and Senegal, it is 30 students per teacher; in Zambia, 43 students per teacher.

- In many countries that participated in PISA-D, a large share of teachers had not completed the current minimum requirements for teaching. In all seven countries, current requirements for beginning teachers in primary and lower secondary school include a teaching practicum as part of pre-service teacher training. But according to teachers who answered a questionnaire distributed to all teachers in schools that participated in PISA-D in Guatemala, Honduras, Paraguay and Zambia, at least $30 \%$ of teachers had not completed any pre-teaching service training.

- The length and level of current teacher-training programmes for primary and lower secondary teachers varies greatly among countries. In Cambodia and Zambia, and for primary school teachers in Senegal, teacher-training programmes result only in upper secondary or post-secondary, non-tertiary qualifications. In addition, according to teachers who completed the PISA-D questionnaire, only about one in four teachers in Senegal had completed a tertiary degree.

- In Cambodia, Paraguay and Senegal, teachers in more advantaged schools and areas tend to have stronger education qualifications than teachers in less advantaged schools and areas. In Cambodia and Senegal, the most disadvantaged schools also have large proportions of novice teachers who have less than five years of experience working as teachers.

- Often, teaching at school is not the only job teachers have. In Cambodia and Senegal, more than half of all teachers who responded to the questionnaire, particularly those in urban regions and those who work in private schools, work as private tutors in addition to teaching at school. In Cambodia and Paraguay, more than one in three teachers also work in another job that is not related to teaching.

- In middle- and low-income countries, the quality of school buildings and instructional resources can have a substantial impact on students' learning outcomes. In Cambodia, many 15-year-olds have no flush toilets (77\%), running water (64\%) or fans (57\%) in their school, according to principals' reports. Similarly, in Zambia, the majority of students do not have access to flush toilets at school (60\%), and many do not have running water (48\%) or electricity (42\%). In Senegal, 48\% of students do not have flush 
toilets at school, and $13 \%$ of students do not have access to separate toilets for boys and girls, even though the vast majority of students (89\%) have access to a place with running water at school. In all countries, school principals reported that school facilities tend to be in worse condition in rural, disadvantaged and/ or public schools than in urban, advantaged and/or private schools.

- The availability of textbooks varies greatly across PISA-D countries. In Senegal and Zambia, the majority of students are in schools whose principals reported that there are not enough textbooks for every student. Only $7 \%$ of students in Senegal and $1 \%$ of students in Zambia attend schools where there is one textbook per student for learning the language of instruction. In both countries, there are so few books that sometimes more than two students need to share a textbook. In Cambodia, Guatemala, Honduras and Paraguay, between 39\% and 52\% of students are in schools where every student has at least one textbook for learning the language of instruction, compared to 95\% in Ecuador. The situation is similar for mathematics textbooks.

\section{Physical condition of school infrastructure across PISA-D countries}

Percentage of student in schools whose principals reported the availability and condition of the following resources:

$$
\because \text { No, not available } \quad \text { Yes, but in poor condition } \quad \text { Yes, but in need of miror repairs } \quad \text { Yes, in good condition }
$$

Lighting

Running Water

Fence or hedge on the school borders

Place with drinkable water

Flush toilets

Indoor plumbing

Fans

Other types of toilets (e.g. latrines, squat holes)

$$
\begin{array}{r}
\text { Access ramp } \\
\text { Cafeteria } \\
\text { Kitchen } \\
\text { First aid room }
\end{array}
$$

Immunisation or healthcare room

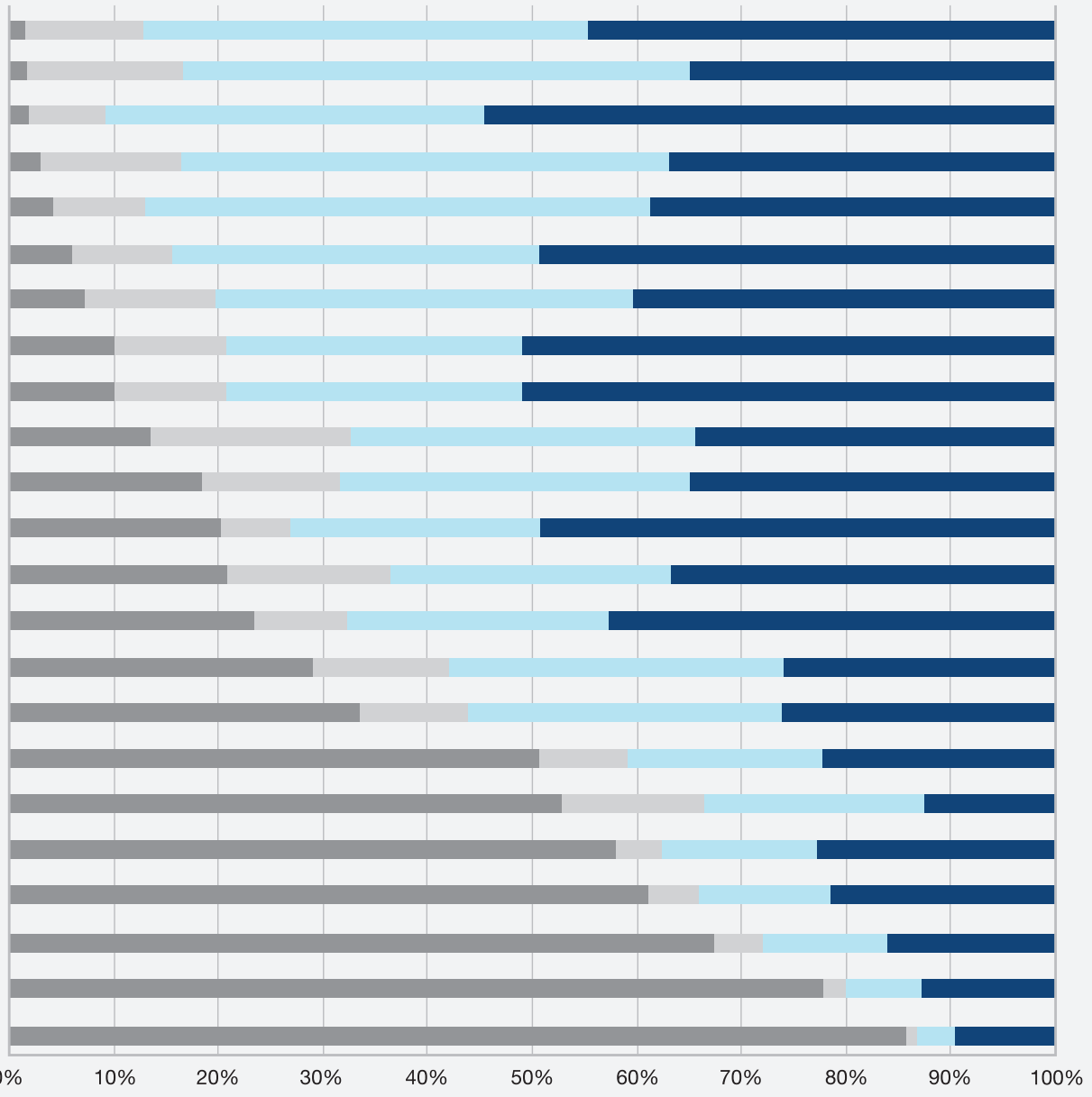

Percentage of students

Source: PISA for Development Database. 


\section{Inclusive learning environments}

- The majority of students in PISA-D countries (88\%) reported that they feel they belong at school, which is higher than the OECD average (73\%).

- On average across the PISA-D countries, 93\% of students reported feeling safe at school. However, in Senegal and Zambia, more than one in ten students reported not feeling safe at school, with the most frequent threats to safety being theft, physical threats and fights. In these two countries, and in Cambodia, more than one in four students also reported feeling unsafe on their way to or on their way home from school.

\section{Learning time}

- About 33\% of students across PISA-D countries reported that they had skipped a whole day of school at least once in the two weeks prior to the PISA-D test, compared to the OECD average of $20 \%$.
- PISA-D also asked students whether they had ever missed school for more than three months in a row; around 15\% reported that they had. The highest percentages were observed in Zambia (24\%), Paraguay and Guatemala (17\%). In all countries, students who had missed school for long periods often cited health problems (their own, or those of family members) as the reason; in Zambia, the inability to pay school fees was a frequently cited reason for missing school.

- In all PISA-D countries, teachers are frequently absent. Most students in the PISA-D countries attend schools where more than one out of three teachers had been prevented from going to work because of a health or family-related problem (e.g. because someone in their family was sick) during the month prior to the PISA test, according to teachers' reports. The vast majority of students across PISA-D countries attend schools where, in the two weeks prior to the PISA test, a teacher did not come to class, arrived late for class, or one or more classes were cancelled, according to reports by more than one in five students.

\section{Students skipping days of school, skipping classes and arriving late for school across PISA-D and OECD countries}

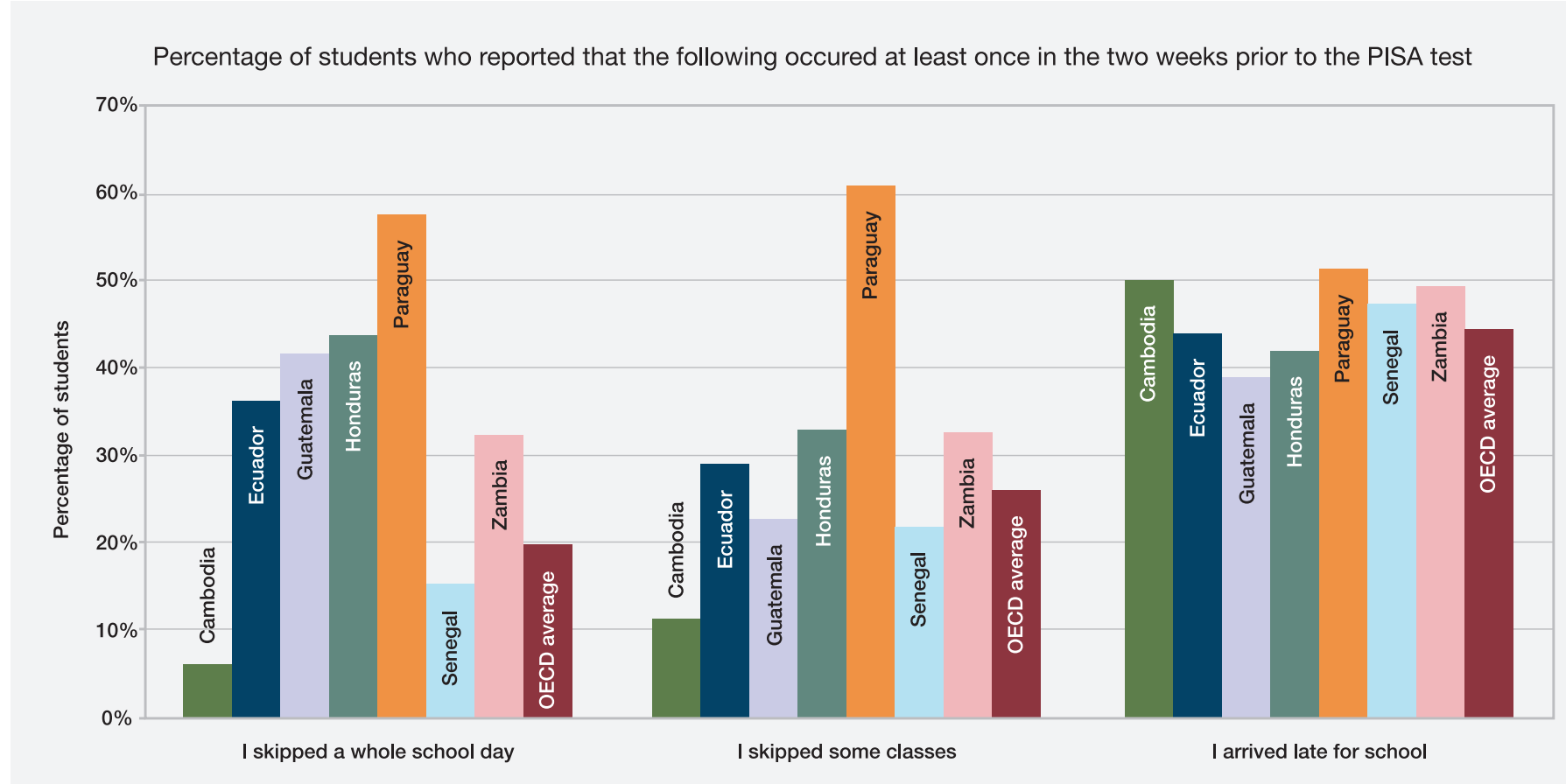

Source: PISA 2015 and PISA for Development Databases.

\section{Quality of instruction}

- Most of the 15-year-old students in PISA-D countries reported positive views about their teachers: 92\% reported that their teachers show an interest in every student's learning; 87\% reported that their teachers are interested in their well-being; and $86 \%$ reported that most of their teachers treat them fairly. 


\section{Teacher support across PISA-D countries}

\section{Percentage of students who agreed or strongly agreed with the following statements}

The teachers give students an opportunity to express opinions

Most of my teachers treat me fairly

The teachers show an interest in every student's learning

If I need extra help, I will receive it from my teachers

Most of my teachers listen to what I have to say

Most of my teacher are interested in my well-being

Most of my teacher are interested in my well-being

I get along well with most of my teachers

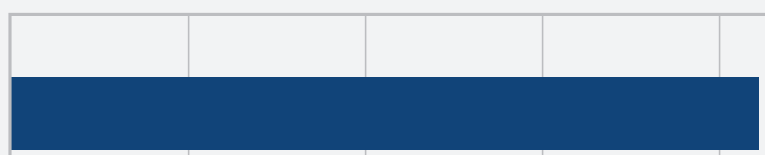

$92 \%$

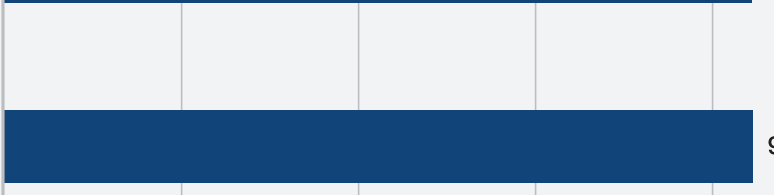

$92 \%$

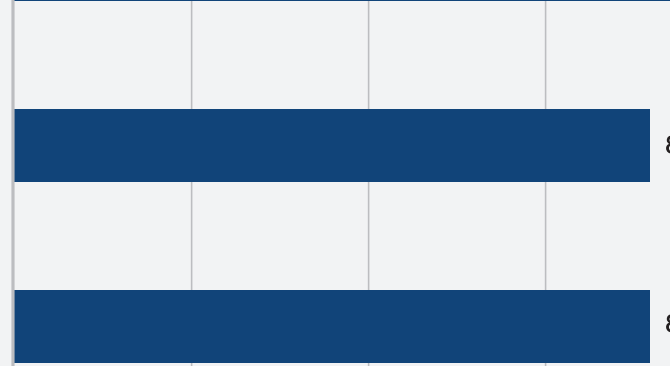

$86 \%$

$86 \%$

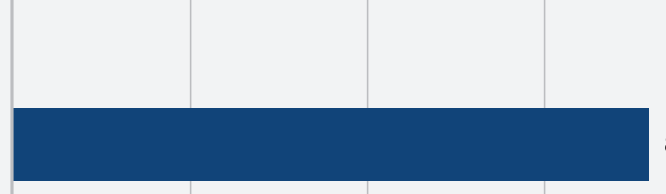

$86 \%$
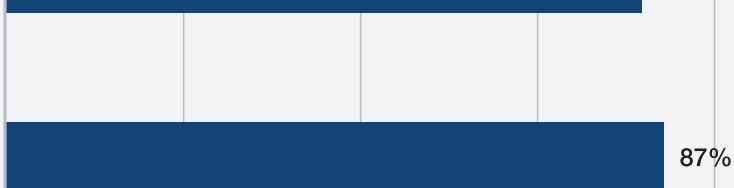

$87 \%$

$92 \%$

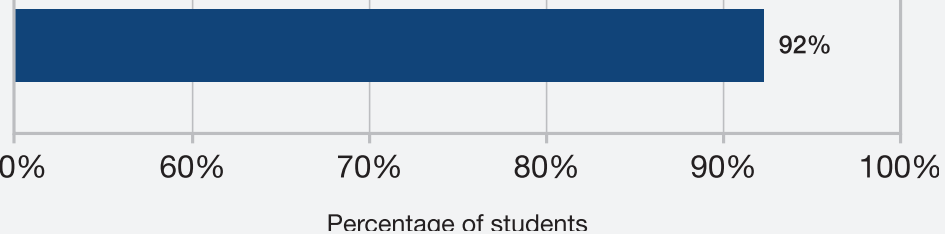

Source: PISA for Development Database.

- Teachers' effectiveness in ensuring that students are engaged and learn during lessons depends critically on their ability to manage students and keep their teaching focused on student learning. On average, as much as $29 \%$ of students across PISA-D countries reported that there is noise and disorder in most lessons, and $25 \%$ reported that students do not start working for a long time after the lesson begins. In Paraguay, Senegal and Zambia, more than $30 \%$ of students so reported.

\section{The wider learning environment: Families and communities}

- PISA-D asked students about the frequency with which their parents or other family members engage in exchanges and activities with them, typically in their homes. This would indicate family support for the student's engagement at school and with learning. Over two-thirds of students reported that, several times a month or more, their parents encourage them to get good grades and talk to them about the importance of completing secondary school. Most students reported that they eat the main meal with their parents several times per week.

- According to teachers' reports, only around $28 \%$ of students in PISA-D countries, on average, are in schools where parents often or always attend parent-teacher meetings. This type of parental involvement in school is greatest in Guatemala (59\%), Ecuador and Honduras (38\%). 


\section{Effective interventions}

\section{Establishing strong foundations for success and improving education outcomes}

The countries that participated in PISA-D face major challenges in establishing in their education systems the five foundations for success identified by the educational prosperity framework used in PISA-D: sufficient material and instructional resources, inclusive learning environments, adequate learning time, quality instruction, and high levels of family and community support. It is clear from the results of the PISA-D assessment that countries must go further towards establishing these foundations for success in order to achieve the desired outcomes, namely, that all students:

- progress through the stages of schooling in the normal way

- achieve at least minimum levels of proficiency in key subjects

- are in good health and have positive attitudes towards school and learning.

Each country has policies and programmes that have had a positive influence on the learning outcomes of their students. For example, the fact that gender differences in attainment and proficiency are not large and are sometimes in favour of girls across PISA-D countries could perhaps reflect countries' efforts to implement gender-equality policies over the past decade.

Countries must also assess the policies that have had a negative effect on learning outcomes and consider the most effective way to offset that impact and chart a path towards improvement. Low standards for hiring teachers, for example, will continue to influence learning outcomes for a long time. Raising those standards sets a course towards higher-quality instruction and classroom management, the effects of which will gradually contribute to improved learning outcomes.

PISA-D assessment results provide countries with a solid database that can help them refine policy priorities and set new goals or targets to improve the foundations for success at all levels of their education systems. The data collected have a lot to say about the allocation of resources and its implications for equity. With reliable data on differences in outcomes and gaps in access to the foundations for success between groups of children and young people, countries can determine whether poor and marginalised populations are given equal opportunities to succeed at school and beyond. The challenge for countries over time is to maintain a focus on these goals or targets, and to track progress towards them by participating in future cycles of PISA and other relevant studies.

\section{Improving allocation of resources in education}

The effective and efficient allocation and use of resources are paramount for ensuring that an education system achieves its objectives. Policy makers in education must regularly assess the distribution of financial, human and physical resources, and determine whether the resources are being used effectively.

Eliminate policies that are costly and have no positive impact.

Grade repetition, for example, is a costly policy, as it requires greater expenditure on education and can delay students' entry into the labour market. Moreover, research has found mainly negative effects of grade repetition on academic achievement and attainment. With one-third of students across PISA-D countries reporting that they had repeated a grade, each country should consider replacing grade repetition with practices that have a more positive impact on outcomes.

In theory, repeating a grade gives students time to "catch up" with their peers if teachers believe they are not yet ready for more advanced coursework. However, grade repetition is a sign of underperformance, and can therefore stigmatise children. Students who have repeated a grade often also demonstrate negative behaviour and attitudes towards school and are more likely to drop out of school. In addition, any positive short-term effects of grade repetition appear to dissipate over time. The practice of grade repetition also reduces the incentive for teachers to diagnose and address underperformance in their classrooms. In systems where grade repetition is limited, teachers tend to assume greater responsibility for students' learning.

In place of grade repetition, countries need to offer support to struggling students to ensure that they master grade-appropriate content and are able to move on to more advanced coursework. Interventions to consider include remedial classes during regular school days and in term breaks, and providing additional learning time for differentiated instruction.

Allocate resources more equitably across schools.

PISA-D results show that school facilities tend to be in worse condition in rural, disadvantaged and/or public schools than in urban, advantaged and/or private schools. There are fewer instructional materials available at these schools as well, and countries often face difficulties in staffing schools in rural regions. Not surprisingly, education outcomes are generally worse for students attending these schools. More equitable resource allocation across schools is necessary to give students in rural, disadvantaged and/or public schools access to the better education opportunities offered to students in urban, advantaged and/or private schools.

Countries must also identify and eliminate practices that could undermine the equity of their education systems. For example, reducing the student-teacher ratio in disadvantaged schools without monitoring the quality of the additional teachers might actually result in an increase in the proportion of novice teachers in those schools. Such an outcome would do little to reduce the performance disparities 
between disadvantaged and advantaged schools. Countries may therefore also need to pay attention to the quality, not just the quantity, of the human resources in disadvantaged schools to ensure equity in education opportunities.

\section{Reduce student truancy and teacher absenteeism.}

Learning time is a key educational resource. In effective schools, academic activities and student performance are valued by both students and teachers, and students rarely miss learning opportunities.

PISA-D results show high truancy rates among students as well as frequent teacher absenteeism. When students arrive late, skip classes, skip entire days or, worse, miss school for months at a time, they fall behind in their classwork and require extra assistance to catch up. For students already struggling with performance, the setbacks to achieving at least minimum levels of proficiency in key subjects are difficult to surmount. Teacher absenteeism disrupts the flow of instruction and threatens achievement of required instruction time. With already limited human resources in many PISA-D schools, teacher absenteeism amplifies the strains on the education system.

Countries need to consider the reasons for student truancy and teacher absenteeism and address them to make better use of the allocated time and resources for learning.

\section{Improving the school environment}

Provide an environment that is conducive to learning.

The most important interventions are those that aim to produce a positive learning environment where everyone plays their part:

- Students are encouraged to attend school regularly, listen to the teacher, treat other students with respect, and not disrupt the flow of instruction.

- Teachers are encouraged and facilitated to co-operate by exchanging ideas or material and to support their students by showing an interest in every student, providing extra help or giving students opportunities to express their ideas.

- The school principal ensures that children with different abilities and from different backgrounds are given opportunities to learn according to their needs, reacts swiftly when behavioural and academic problems arise, and ensures that a range of extracurricular activities are offered at school.

- Parents are encouraged to participate in a wide variety of school activities, not only when their child has behavioural or academic problems, and interact with other parents.

- Governments use assessments and information systems, already in place in most countries and economies, and informal mechanisms to identify individual schools that are struggling and may need special assistance.
Ensure that educators set the tone for a caring and inclusive school community.

An important aspect of inclusive education is ensuring that principals and teachers are prepared and willing to address the diversity of learners, and particularly to respond to the special needs of students with disabilities and of students with learning difficulties. In addition, it is important that principals and teachers see it as their responsibility to educate all children.

\section{Improving the quality of instruction}

Make teaching more effective.

Most goals of school education are achieved - or not - through students' and teachers' interactions in the classroom. Improving the effectiveness, efficiency and equity of schooling depends, in large measure, on ensuring that competent people want to work as teachers, that their teaching is of high quality and that high-quality teaching benefits all students.

All countries face the question of how to improve the quality of instruction. As a starting point, countries need to devise a system of motivating, attracting, developing and retaining high-quality teachers and school leaders, and creating a work organisation in which they can thrive.

PISA-D results also point to a need for all countries to strengthen pre-service training requirements and improve teacher preparation, especially for teachers working in schools lacking the material and instructional resources that support better learning outcomes. The quality of instruction must also be evaluated throughout a teacher's career, providing him or her with feedback for improvement, professional development opportunities that align with teaching goals, and instructional resources aligned with a competencybased curriculum.

\section{Strengthening family and community support for education}

PISA data show that 15-year-old students whose parents routinely engage in home-based activities with them, such as eating a meal together or spending time "just talking", not only score higher, but also are more satisfied with their life. And students who regard their parents as being interested in their school life perform better, report higher achievement motivation, and are more likely to be highly satisfied with their life than students who report a lack of parental interest.

Like PISA, PISA-D data show that for some parents, spending time just talking with their child is a rare occurrence. Parents can also find it difficult to participate in their child's school life because of inflexible work schedules, lack of childcare services or language barriers. Schools can do a lot to help parents overcome these barriers. First and foremost, school leaders must work to ensure that everyone in the community, particularly parents, recognises the importance of school and learning. 


\section{For more information}

Contact: Michael Ward (michael.ward@oecd.org)

See: The PISA-D school-based assessment results are published in national reports produced by Cambodia, Ecuador, Guatemala, Honduras, Paraguay, Senegal and Zambia in collaboration with the OECD. These national reports are being released by each country over the course of 11-14 December 2018. The international PISA-D data set can be found at www.oecd.org/pisa/pisa-for-development/.

OECD (2018), PISA for Development Assessment and Analytical Framework: Reading, Mathematics and Science, OECD Publishing, Paris, http://dx.doi.org/10.1787/9789264305274-en.

UNESCO (2015), Education 2030 Incheon Declaration and Framework for Action: Towards Inclusive and Equitable Quality Education and Lifelong Learning for all, United Nations Educational Scientific and Cultural Organization, Paris, www.unesco.org/new/fileadmin/ MULTIMEDIA/HQ/ED/ED/pdf/FFA Complet Web-ENG.pdf.

UN (2015), Transforming our World - the 2030 Agenda for Sustainable Development, United Nations, New York, www.un.org/pga/ wp-content/uploads/sites/3/2015/08/120815 outcome-document-of-Summit-for-adoption-of-the-post-2015development-agenda.pdf.

This paper is published under the responsibility of the Secretary-General of the OECD. The opinions expressed and the arguments employed herein do not necessarily reflect the official views of OECD member countries.

This document, as well as any data and map included herein, are without prejudice to the status of or sovereignty over any territory, to the delimitation of international frontiers and boundaries and to the name of any territory, city or area.

This work is available under the Creative Commons Attribution-NonCommercial-ShareAlike 3.0 IGO (CC BY-NC-SA 3.0 IGO). For specific information regarding the scope and terms of the licence as well as possible commercial use of this work or the use of PISA data please consult Terms and Conditions on www.oecd.org. 
